\title{
Rational for conducting PTSD Researchand Challenges of Recruiting and Training Volunteers to Screen and Treat PTSD among the Nepal 2015 Earthquake Survivors
}

\author{
Arun Jha, ${ }^{1}$ Suraj Shakya ${ }^{2}$ \\ 'Psychiatry Chapter, Nepalese Doctors' Association UK, ${ }^{2}$ Department of Psychiatry and Mental Health, TU Teaching Hospital, \\ Kathmandu, Nepal.
}

\section{ABSTRACT}

Post-traumatic Stress Disorder (PTSD) is common psychiatric morbidity among earthquake survivors, and if untreated people suffer from it for years. Government of Nepal and NGOs provided various short-term mental health services to the victims of the 2015 earthquake in Nepal, but there was no plan or provision for long-term mental health problems. The prevalence of PTSD following natural disasters depends on various local factors requiring understanding and further investigation before identifying affordable evidence based interventions. This paper discusses the need for PTSD research among the survivors of the 2015 earthquake in Nepal, and describes the challenges and difficulties of recruiting and training PTSD volunteers.

Keywords: earthquake; narrative exposure therapy; Nepal; prevalence; PTSD.

\section{INTRODUCTION}

In April 2015, a devastating earthquake struck Nepal, with an epicentre $77 \mathrm{~km}$ northwest of Kathmandu when over 8,000 people were killed and nearly 18,000 people injured. Earthquakes, compared to other natural disasters, carry the risk of severe damage and injury. There is no gap or stability period between relief and recovery.Also, rather than being a circumscribed event with a defined endpoint, earthquakes aftershocks continue to affect people's mental health. While general distress following an earthquake returns to normal within a few months, post-traumatic stress disorder (PTSD) takes years to subside. ${ }^{1}$ The prevalence of PTSD in earthquake survivors varies from 10.3 to $66 \%,{ }^{2}$ and depends on the level of trauma exposure and proximity to the epicentre of the earthquake.

This paper outlines the challenges of identifying, recruiting and training mental health volunteers in providing mental health services for the earthquake survivors with PTSD.

Lessons from past emergency efforts in Nepal

Encouraged by the work of major humanitarian aid agencies such as Médecins Sans Frontières in 1990s, and International Federation of Red Cross and Red Crescent Societies in 2000s, the United Nations commissioned guidelineson mental health and psychosocial support in emergency setting resulting in Inter-Agency Standing Committee's guidelines. ${ }^{3}$ The IASC guidance insists that psychosocial support must be a part of all assessments and interventions in all emergencies anywhere in the world. The composite

Correspondence: Dr. Arun Jha, Logandene Care Unit, Hertfordshire Partnership University NHS Foundation Trust, Ashley Close, Hemel Hempstead, Hertfordshire, HP3 8BL, UK. Email: arunjhauk@gmail. com, Phone: +44-1442 215060 . 
term mental health and psychosocial support (MHPSS) has been used by the IASC not only to protect and promote psychosocial wellbeing but also to prevent and treat mental disorders. A four-layered system of complimentary support has been recommended to meet the needs of different groups. These include: (a) basic services and security for all affected people, (b) community and family support for a smaller number of people who are able to maintain their mental health if they receive help in accessing key community and family support, (c) focused non-specialist supports, including psychological first aid and basic mental health care by primary care workers, and (d) specialist services. The IASC MHPSS Reference Group, consisting of over 30 members, was established in December 2007 to support and advocate for the implementation of the IASC Guidelines. In 2009, a project was set up in Nepal for the adaptation and application of the IASC Guidelines for MHPSS Support in Emergencies, resulting in the Nepalese translation of the guidelines.

Psychosocial and mental health programs have been set up in previous emergencies in Nepal, including those for former child soldiers, for families of ling-term missing people, and for refugees. ${ }^{4}$ To date Nepal's PTSD studies have primarily focused on populations affected by political violence during the Maoist People's War ${ }^{5,6}$; and Bhutanese refugees displaced to the southeast of Nepal. ${ }^{7,8}$ Based on figures on these populations and estimates based on international populations affected by humanitarian crises, it has been predicted that around $15-20 \%$ will have mild or moderate mental disorders such as depression, anxiety and PTSD); and around $3-4 \%$ will have severe mental disorders such as psychosis and severe depression. ${ }^{4}$ Thapa\& Hauff $^{6}$ conducted a mental health prevalence study on the internally displaced persons during the Maoist insurgency in Nepal in late 1990s and early 2000s resulting in a death toll of over 13,000 people and displacement of hundreds and thousands from their homes. They reported a very high prevalence of anxiety, depression, and PTSD symptoms - $80.7 \%, 80.3 \%$, and $53.4 \%$ respectively.

Mental health services in Nepal are primarily hospital based with negligible presence in the community. ${ }^{9}$ Mental health has recently been included in Nepal Health Sector Support Program (NHSP-II), a non-communicable disease multi stakeholder action plan 2014-2020. ${ }^{10}$ The Government of Nepal, however, lacks a focal point for emergency mental healthand psychosocial support (MHPSS).

\section{Mental health and psychosocial initiatives following the earthquake}

Following the devastating earthquake in April 2015, a IASC MHPSS Reference Group was constituted in Nepal to monitor the PSS sub-cluster under the Protection Cluster, chaired by UNICEF, and the $\mathrm{MH}$ sub-cluster under the Health Cluster, chaired by WHO. ${ }^{4} \mathrm{~A}$ desk review summarises existing information on mental health and psychosocial wellbeing in Nepal to help people responding to the earthquakes and to avoid collecting information in needs assessments that is already available. ${ }^{4} \mathrm{t}$ is known that $\mathrm{MH}$ problems prior to traumatic exposure increase the risk of PTSD, substance abuse, and other MHPSS problems after trauma. The challenge for the $\mathrm{MH}$ sub-cluster was the high burden of mental illness prior to the earthquake requiring intervention, while planning emergency mental health services for those following the earthquake.

Natural disasters pose the difficulties in reconciling the two contradictory needs: first, the need for speed, to move quickly in response to a disaster to save lives, provide food and housing, and establish order and security; and secondly, the need to take time to accurately assess and understand the situation in all its complexity, to grasp the needs and desires of the affected community, and to involve the community in the short and long-term recovery efforts. ${ }^{11}$ The Nepalese Doctors' Association (NDA) UK, like several other national and international organisations willing to help Nepal, struggled with this paradoxical challenge of needing to 'go slow' in order 'to go fast'. At the request of the Nepalese Embassy in London, NDAUK sent three medical teams to Nepal within two weeks of the earthquake. On their return, the volunteers' message was not to send any more medical team, butto offer help in psychosocial support and recovery. There was a fear of outbreaks diseases, but fortunately that did not happen, for epidemics are rare after geophysical disasters. ${ }^{12} \mathrm{By}$ that time, the Mental Health sub-cluster and the Nepal Medical Association, in conjunction with several medical colleges and NGOs had planned middlelayer support at community and non-specialist levels in most of the 14 earthquake-affected districts. While this short-term psychosocial support was necessary, there was no plan for long-term intervention for victim's psychological problems such as fear, anxiety, anger, depression or PTSD.

\section{Volunteers for PTSD screening and therapy}

In addition to identifying earthquake survivors with suspected PTSD, there was a need to decide which form of therapy was appropriate for them. Trauma-focused psychotherapieshave been found more effective for treating PTSD than drug therapy. However, as these therapies are usually administered on an individual basis by qualified therapists over a number of sessions, they are not possible to be used after large-scale 
disasters in low-income countries. In many situations, Western views of appropriate treatments are thrust upon developing countries, whose cultural views do not correspond with the treatments being provided. Therefore, after a thorough literature review and discussion with experienced international scientists, a shorter version of Narrative Exposure Therapy (NET) the revised NET (NET-R) developed by Zang el $\mathrm{al}^{13}$ in China, was chosen for Nepal earthquake survivors.

Like other low-income countries, there is a shortage of qualified mental health professionals in Nepal. Primary care health staff do not possess adequate knowledge and training to manage PTSD in the community. Therefore, we decided to recruit and train non-specialist volunteers. The first author approached the co-ordinator of the Mental Health sub-cluster, and the second author approached the TU central department of Psychology to encourage final year postgraduate students to volunteer for the earthquake related PTSD work.

Initially, we wanted to work in the worst affected areas outside Kathmandu. But it was very difficult to recruit volunteers immediately following the earthquake, as mental health professionals living in Kathmandu were had to support and assure their own families. Therefore, we chose two earthquake-affected villages near Kathmandu: Khoijavillage in Bungmativillage development council (Lalitpur district) and Panga village in Kirtipur municipality.

\section{Mental Health Training}

We organised two sets of training programmes in Kathmandu in July 2015: first by the Nepalese Doctors' Association (NDA) UK and the Department of Psychiatry and Mental Health at the TU Teaching Hospital, Maharajgunj (4-10 July), and the second by the NDAUK and the department of Psychology at TU central campus, Kirtipur (11-16 July). The first training consisted of a 2-day classroomworkshopand 5-day fieldwork in Bungmati.The first day of the training focused on trauma-focused counselling while the second day was all about PTSD, revised Narrative Exposure Therapy (NET-R), and research work, followed

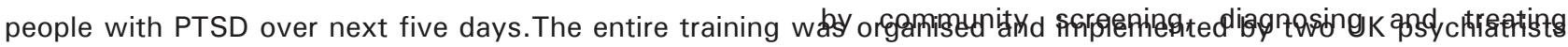
(including the first author, AJ), and supported by the second author (SS). Table 1 provides the details of the training programme.

\begin{tabular}{|c|c|c|c|}
\hline \multirow[b]{2}{*}{ Sessions } & Day 1 & Rav 2 & Fieldwork (Day 3-7) \\
\hline & $\begin{array}{l}\text { (Trauma-focused PSS } \\
\text { module) }\end{array}$ & (PTSD \& NET-R module) & $\begin{array}{l}\text { (PTSD screening, diagnosis and } \\
\text { Therapy) }\end{array}$ \\
\hline \multirow{3}{*}{ Morning } & $\begin{array}{l}\text { Experience and challenges } \\
\text { of providing psychosocial } \\
\text { support }\end{array}$ & $\begin{array}{l}\text { Signs and symptoms of } \\
\text { acute stress, PTSD, and their } \\
\text { treatment options }\end{array}$ & $\begin{array}{l}\text { Briefing and review of PC-PTSD } \\
\text { screening and PCL- } 5 \text { instruments }\end{array}$ \\
\hline & $\begin{array}{l}\text { Psychosocial impact of } \\
\text { earthquake trauma }\end{array}$ & $\begin{array}{l}\text { Theoretical model and } \\
\text { Elements of NET }\end{array}$ & $\begin{array}{l}\text { Verbal consent \& Door to door } \\
\text { screening in pairs }\end{array}$ \\
\hline & Grief in earthquake survivors & $\begin{array}{l}\text { NET Steps - psychoeducation, } \\
\text { grounding, lifeline and working } \\
\text { up a narrative }\end{array}$ & $\begin{array}{l}\text { Diagnostic interview of PTSD } \\
\text { screen-positive individuals }\end{array}$ \\
\hline \multirow{3}{*}{ Afternoon } & Psychosocial counselling & NET practice in pairs & $\begin{array}{l}\text { Group supervision and review of } \\
\text { morning work }\end{array}$ \\
\hline & Secondary stress & $\begin{array}{l}\text { Outline of fieldwork and } \\
\text { practice PTSD screening and } \\
\text { diagnosis }\end{array}$ & $\begin{array}{l}\text { Psychoeducation and narrative } \\
\text { exposure therapy sessions }\end{array}$ \\
\hline & Questions and answers & Questions and answers & $\begin{array}{l}\text { Group supervision, review of } \\
\text { afternoon work, and planning for the } \\
\text { following day }\end{array}$ \\
\hline
\end{tabular}

Throughout the training, participants were encouraged to interact with each other and with the supervisors in an informal and friendly environment.

The Kirtipur training for psychologists was of only one day on PTSD, NET-R and fieldwork, as the graduates were already aware of basic trauma-focused psychosocial issues.

\section{PRELIMINARY FINDINGS}

We managed to recruit and train 15 mental health 
volunteers and 28 psychology graduates from the central department of psychology and from the local women's college (Padma Kanya campus) in Kathmandu. Table 2 shows the background details and pre-training knowledge of mental illness and PTSD of 12 volunteers (out of 15) who completed a survey questionnaire adapted from previous studies. ${ }^{14}, 15$ The questionnaire had 14 items -4 on background, and 10 on PTSD.

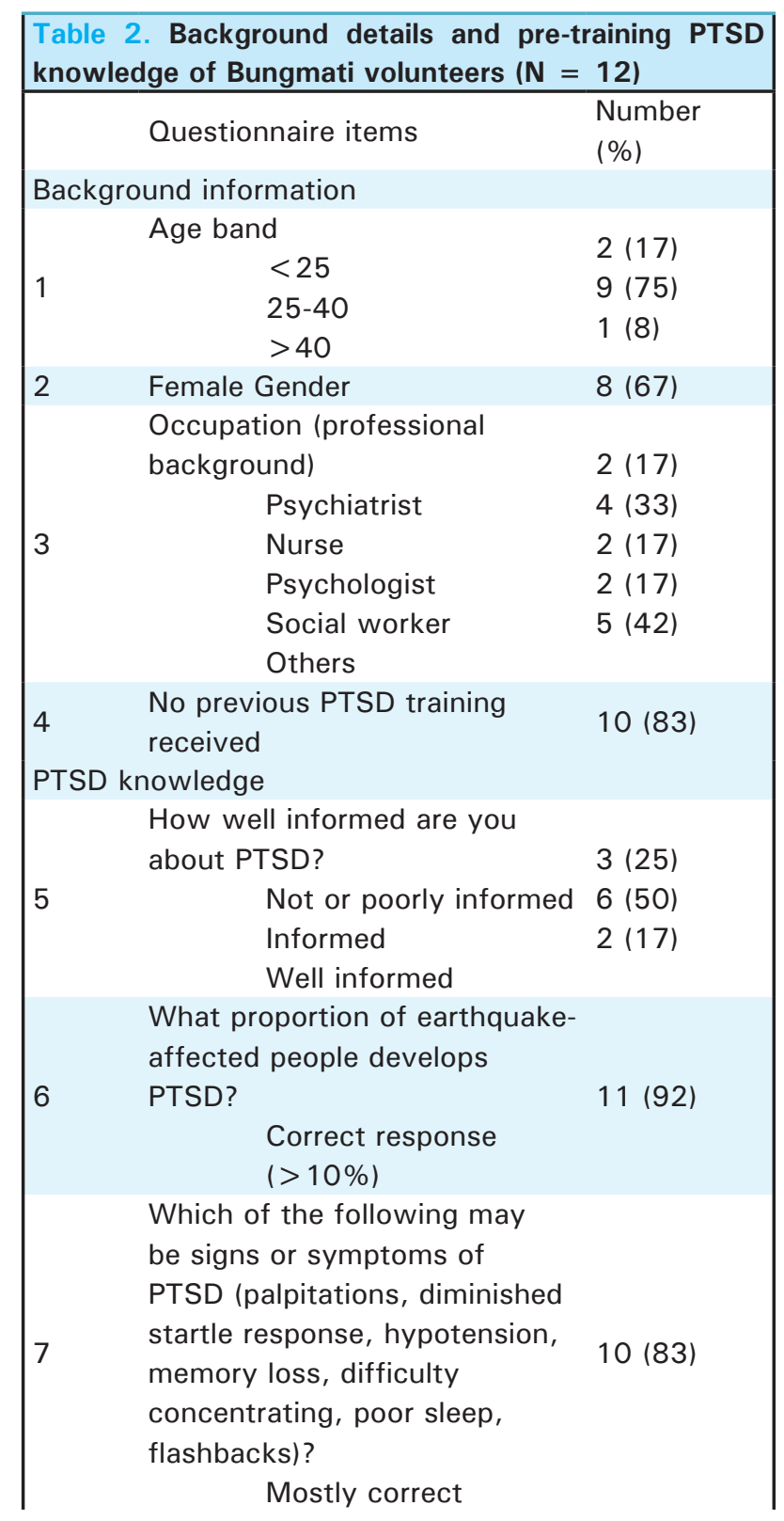

Which of the following are appropriate in the clinical management of PTSD

8 (tricyclic antidepressants, benzodiazepines, SSRIs, typical $2(17)$ antipsychotics, EMDR, family therapy)?

Mostly correct PTSD is an important health concern among earthquake survivors:

Agree (correct)

Chronic mental illness and comorbidities can be avoided if

10 PTSD is diagnosed and treated $12(100)$ early:

Agree (correct)

PTSD malingering in

earthquake victims is a

common occurrence:

Neutral or disagree (correct)

Screening all earthquake victims in Nepal will be too time-consuming:

Agree (correct)

There are enough PTSD-trained mental health professionals in

\section{Nepal:}

Disagree (correct)

I feel I have received adequate education and training regarding diagnosis and

\section{Agree}

Neutral

A large majority of the volunteers were female between the age of 25 and 40 . Most of them appeared knowledgeable about PTSD apart from its clinical management, and rated themselves as 'informed', but they had not received any previous PTSD training(Table 2). Not surprisingly, a high proportion of volunteers expressed the need for further PTSD training.

A couple of volunteers contacted the first author after the training for further help and guidance. An example is given in Box 1 .

\section{Box 1: Email request from a psychology volunteer}

"I have collected some PTSD results but I have one query. I have meet one lady whose PTSD score is $38+$ and she is suffering from some psychological problem too like stress, tension, etc. I met her in Kathmandu and talked with her for about an hour in my home. She started crying when she shares her feelings with me. At 
that point I told her to end the session but she requested to continue, as she had no time to come again for the sessions. Therefore, I continued the session, which lasted 5 hours during which she experienced her hot memories related to the earthquake. She asked me to keep her name confidential, and did not give me her cell number. Now I am confused about hot to complete her narration and complete the therapy."

The following quotes from the trainers capture the mood of the entire training and fieldwork (Box 2).

\section{Box 2}

Quote 1 (Dr Rajesh Nehete, British Psychiatrist of Indian origin)

"That was my first visit to Nepal, and I could not believe how people were able to recover so quickly and function normally in Kathmandu after such a devastating earthquake only a few weeks ago. The participants were so friendly and kind that $I$ felt as if I had known them for a long time. They were keen to learn, work as a team, and help people affected by the earthquake with great sensitivity, love and affection. Although I have not seen Nepal at all, I now know that tourists are more impressed by the people of Nepal than mountains and forests!"

Quote 2(Dr ArunJha, British Psychiatrist of Nepalese origin)

"I have been going to Nepal at least once a year since I came to the UK in 1986, and through the NDAUK I have been involved in various mental health work in last 10 years. The number of psychiatrists and mental health nurses has definitely increased in 15 years, but the services are mainly hospital based with very little to offer in the community. I was very impressed with the initial psychosocial work done, but equally disappointed with the lack of any long-term plan. This is not due to lack of willingness, but due to lack of vision and clinical leadership. In my experience, a few psychiatrists and psychologists came to our training out of curiosity, but the vast majority appreciated our effort and were totally devoted to the cause of earthquake victims without expecting too much in return. We trained nearly 50 people in July, and if even half of them join us in our next project in six months time, we will feel vindicated"

\section{Quote 3 (SurajShakya, Nepalese Psychologist and PTSD research coordinator)}

"The post disaster scenario has brought challenges for mental health sector in Nepal, which created opportunities to help and learn. Training in Narrative Exposure Therapy for PTSD is one example. The training was relevant and the fieldwork reinforced the idea that it can be learned and practiced with minimal supervision. The trainees seemed quite enthusiastic as seen by their active participation. I appreciate the effort and skills of the facilitators who came all the way from the UK.

\begin{tabular}{|c|c|}
\hline \multicolumn{2}{|c|}{$\begin{array}{l}\text { Table 3. Key lessons learnt for recruiting and training } \\
\text { non-specialist mental health volunteers }\end{array}$} \\
\hline Domains & Lessons for future PTSD work in Nepal \\
\hline $\begin{array}{l}\text { Recruitment } \\
\text { of } \\
\text { volunteers }\end{array}$ & $\begin{array}{l}\text { - Volunteers should be local } \\
\text { - Vraduates, preferably psychologists } \\
\text { - allowanteers expect travel and daily } \\
\text { One volunteer can provide NET-R to } \\
\text { not more than } 4 \text { PTSD patients per } \\
\text { day; number of volunteers should } \\
\text { be recruited accordingly } \\
\text { - Volunteers should be informed } \\
\text { at the outset of their minimum } \\
\text { commitments regarding timing } \\
\text { and duration of their involvement, } \\
\text { preferably fulltime for two weeks } \\
\text { including } 2 \text { days of training }\end{array}$ \\
\hline $\begin{array}{l}\text { Training of } \\
\text { volunteers }\end{array}$ & $\begin{array}{l}\text { - A minimum of 2-day day PTSD } \\
\text { related classroom training is } \\
\text { required to cover psychological } \\
\text { impact of natural disaster on } \\
\text { survivors including acute stress and } \\
\text { PTSD, and theory and practice of } \\
\text { narrative exposure therapy } \\
\text { Daily supervision of volunteers } \\
\text { during the fieldwork } \\
\text { Residential training at the study site } \\
\text { may foster group learning and team } \\
\text { working } \\
\text { Therapy manual written in simple } \\
\text { English with Nepalese case histories } \\
\text { was appreciated by the volunteers } \\
\text { Volunteers suggested that future } \\
\text { trainings in the should be slightly } \\
\text { longer and supervision sessions } \\
\text { more structured." }\end{array}$ \\
\hline
\end{tabular}

\section{SUMMARY \& CONCLUSIONS}

Currently, there are not enough psychiatrists and mental health nurses in Nepal to deliver mass level mental health interventions in disaster-affected areas outside Kathmandu. People were so scared of the aftershocks of the earthquake that a high number had left Kathmandu in the first three months of the earthquake, and specialist mental health workers were busy delivering urgent psychosocial support.Following the earthquake, the IASC MHPSS reference group, in collaboration 
with several organisations, carried out assessment of immediate mental health and psychosocial needs with a view to tailor interventions. ${ }^{4}$ They provided psychological first aid to people in distress, but their long-term mental health needs were not addressed, and PTSD was not included in their priority list. This paper has highlighted the gaps in Nepal's strategic plans for the specific needs of people suffering from PTSD.

Table 3 provides the difficulties in identifying, recruiting, and training volunteers as well as lessons learnt for future PTSD work in Nepal.

\section{CONCLUSIONS}

Although individual meditative and ritual practices are often adopted in rural Nepal as a way of restoring mental and emotional health, there is no effective treatment available in these practices. Moreover, PTSD is not recognised as a mental disorder requiring treatment in developing countries like Nepal. Non-specialist mental health workers and psychology graduates in Nepal appear keen to learn about PTSD and they are willing to work in the community with minimum incentives.

\section{ACKNOWLEDGEMENTS}

We would like to thank Dr Rishav Koirala of WHO Nepal for helping to recruit mental health nurses, to Prabhat Pradhan of Mental Health First Aid Nepal for identifying social workers, and Professor Shanta Niraula for providing psychology graduates and excellent training facilities and support at Kirtipur Campus.

\section{REFERENCES}

1. Guo J, Wu P, Tian D et al. Post-traumatic stress disorder among adult survivors of the Wenchuan earthquake in China: a repeated cross-sectional study. J Anxiety Disorders. 2014;28:75-82.

2. Fu Y, Chen $Y$, Wang J et al. Analysis and prevalence of PTSD and its influencing factors among college students after the Wenchuan earthquake. Child and Adolescent Psychiatry and Mental Health. 2013;7:1.

3. Inter-Agency Standing Committee (IASC). IASC Guidelines on Mental Health and Psychosocial Support in Emergency Settings. Geneva: IASC; 2007.

4. Inter-Agency Standing Committee (IASC) Reference Group for Mental Health and Psychosocial Support in Emergency Settings. Nepal Earthquakes 2015: Desk Review of Existing Information with Relevance to Mental Health and Psychosocial Support; Kathmandu, Nepal; 2015.

5. Luitel, NP, Jordans MJ, Sapkota RP, Tol WA, KohrtBA, Thapa SB, Komproe IH, Sharma B. Conflict and mental health: a cross-sectional epidemiological study in Nepal. SocPsychiatry. PsychiatrEpidemiol, 2013;48(2):183-93.

6. Thapa SB, Hauff E. Psychological distress among displaced persons during an armed conflict in Nepal. Soc Psychiatry PsychiatrEpidemiol, 2005;40:672-9.

7. Shrestha NM, Sharma B,Ommeren MV, Regmi S, Makaju R, Komproe, I, Shrestha GB, and de Jong JT. Impact of torture on refugees displaced within the developing world: symptomatology among Bhutanese refugees in Nepal. JAMA. 1998;280(5): p. 443-8.

8. Tol WA, Komproe IH, Thapa SB, Jordans MJD, SharmaB, and De JongJ. Disability associated with psychiatric symptoms among torture survivors in rural Nepal. J Nervous and Mental Disease. 2007;195(6): p. 463-9.
9. Jha A, Adhikari SR. Mental health services in new Nepal observations, objections and outlook for the future. J Nepal Med Assoc. 2009;48(174):185-90.

10. Upadhaya N, Luitel NP, Koirala $\mathrm{S}$ et al. The role of mental health and psychosocial support in nongovernmental organisations: reflections from post conflict Nepal. Intervention. 2014;12(1):113 -28.

11. Scribner M, Herzer L.After the disaster: rebuilding communities. Woodrow Wilson International Centre for Scholars: Washington DC. 2011.

12. Toole, M. Communicable Diseases and Disease Control. In E. K. Noji (Ed.), The public health consequences of disasters (pp. 79-100). New York: Oxford University Press. 1997.

13. Zang $\mathrm{Y}$, Hunt N, \& Cox T (2014.) Adapting narrative exposure therapy for Chinese earthquake survivors: a pilot randomized controlled feasibility study. BMC Psychiatry. 2014;14:262.

14. Munro CG, Freeman CP, Law R. General practitioners' knowledge of post-traumatic stress disorder: a controlled study. BJGP. 2004;54:843-7.

15. Mckenzie K, Smith DI. Posttraumatic stress disorder: Examination of what clinicians know. $\quad$ C 1 i n i c a 1 Psychologist. 2011;10(2):78-85.

16. Jha A, Nehete R, Zang $Y$ et al. Post-traumatic stress disorder (PTSD) among Nepal 2015 earthquake survivors: feasibility of revised narrative exposure therapy. BJPsych International (submitted for publication, September 2016). 